\title{
Governance mode choice in collaborative Ph.D. projects
}

\author{
Negin Salimi • Rudi Bekkers • Koen Frenken
}

Published online: 19 September 2014

(C) Springer Science+Business Media New York 2014

\begin{abstract}
Joint Ph.D. projects are a prominent form of research collaboration, connecting universities to firms and public research organizations. When entering into such collaborations, partners need to make choices regarding a project's governance. This paper investigates how a university and its partners govern such projects, including decisionmaking, daily management and disclosure policies. Earlier studies show that shared governance modes have had a higher success rate than centralized governance modes. Nevertheless, more than two thirds of the 191 joint Ph.D. projects we investigated opted for centralized rather than shared governance. Our findings show that: (1) geographical and/or cognitive distance render the adoption of a shared governance mode less likely; (2) the partner controlling critical resources tends to centralize governance, and (3) partnering firms are more likely to put restrictions on publication output than public research organizations. We therefore recommend that universities and their partners take these aspects into account when selecting such projects.
\end{abstract}

Keywords University-industry collaboration - Collaborative Ph.D. project · Shared governance · Centralized governance - Proximity · Resource imbalances · Publication disclosure

N. Salimi $(\bowtie) \cdot$ R. Bekkers $\cdot$ K. Frenken

School of Innovation Sciences, Eindhoven University of Technology, Eindhoven, The Netherlands e-mail: n.salimi@tue.nl

R. Bekkers

e-mail: r.n.a.bekkers@tue.nl

K. Frenken

e-mail: k.frenken@uu.nl

R. Bekkers

Dialogic Innovatie and Interactie, Utrecht, The Netherlands

Present Address:

K. Frenken

Innovation Studies, Copernicus Institute of Sustainable Development, Utrecht University, Utrecht, The Netherlands 


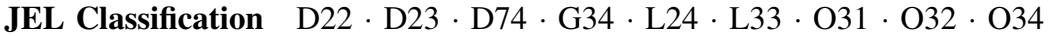

\section{Introduction}

Knowledge production can be seen as a process in which scarce resources are exploited to produce a specific output. From this economic viewpoint, the question of knowledge production can be outlined as a traditional 'make-or-buy' decision (Williamson 1975); a firm can purchase knowledge through market transactions (e.g. consultancy, license agreements) or develop knowledge in-house through $\mathrm{R} \& \mathrm{D}$ investment. If transaction costs are relatively low, a firm will opt for market transaction, while if transaction costs are relatively high, a firm will favor in-house production.

Inter-organizational collaboration provides an alternative to make-or-buy. Although collaborative arrangements in knowledge production have always existed in certain sectors, dating back to the Industrial Revolution (Nuvolari 2004), R\&D collaboration has become especially salient in high-technology industries from the 1980s onwards (Powell et al. 2005; Hagedoorn et al. 2000). The popularity of collaboration can be appreciated by bearing in mind the disadvantages of both in-house production and market purchase. With the growing complexity and pace of innovation, it is becoming increasingly harder for firms to master all the relevant knowledge domains (Granstrand et al. 1997). Hence, to rely solely on in-house knowledge production is too costly and risky under most conditions. At the same time, markets for knowledge are far from perfect, mainly because knowledge is an experience good: its economic value can only be evaluated ex post. The growing complexity and pace of innovation render such markets even more imperfect. As a result, firms often engage in inter-organizational research collaborations to pool resources, to exploit complementary assets, and to share the risks inherent in R\&D (Teece 1986).

Inter-organizational collaboration in knowledge production is a "mixed bag". Actors may have different motives ranging from technology sensing and basic R\&D, joint product development and value chain optimization, to standard-setting and co-patenting. Moreover, forms of governance range from informal networking to R\&D partnerships and equity joint ventures. Hence, the core research challenge so far has been to identify the choice of knowledge production mode for different motives and under varying environmental conditions (Teece 1986).

Here, we focus on collaborations involving universities. In present day science-based innovation processes, universities have been central in the R\&D process. There is clearly a rising trend in the number of collaborations between universities on the one hand and firms or public research organizations (PROs) on the other, as indicated by co-publications (Ponds et al. 2007). Firms and PROs have several reasons to collaborate with universities (Liebeskind et al. 1996; Ponds et al. 2007), namely: (1) in many knowledge domains, cutting-edge knowledge can only be gained by actively working together with universities as such knowledge is not yet codified, (2) universities often have unique resources including databases and research facilities that would be too expensive for firms or PROs to construct in-house, (3) through collaboration, university knowledge can immediately be made relevant to the specific problem-context of the firm or PRO.

Doctoral candidates are key producers of new knowledge and are also considered the main channels for transferring knowledge to firms (Thune 2009). The relationship structure between the three main partners in this collaboration (Ph.D. candidate, university and its partner) makes the collaboration governance very complex. The specificity of joint Ph.D. 
projects not only stems from the nature of the partnership, but also from its duration (3 years or longer) and type of knowledge (scientific research). Despite this specificity, joint $\mathrm{Ph} . \mathrm{D}$. projects are far from homogeneous regarding the micro-level structure of governance, as the exact mode of governance varies considerably. In particular, we can distinguish between a "shared" governance structure where project management is a shared responsibility and decisions are made by mutual agreement, and a "centralized" governance structure where the responsibility for project management and authority in decision-making are allocated to one of the two parties.

Generally speaking, collaboration in scientific research is organized using shared governance structures (Gibbons et al. 1994). In most instances, distributing authority among team members involved in scientific research promotes flexibility, creativity and efficiency (Liebeskind et al. 1996; Shrum et al. 2007). In the specific case of joint Ph.D. projects between a university partner and an external partner, one study found that projects with a shared governance structure did indeed have more outputs than those with centralized governance, where the governance was dominated by one of the partners (Salimi et al. 2013). Hence, the question arises under what conditions parties opt for a shared or centralized governance structure.

Joint Ph.D. projects are, by nature, organizationally complex, involving at least two partner organizations and the Ph.D. candidate in question. What is more, the return on a project's investments is fundamentally uncertain. Consequently, contingencies are hard to foresee, let alone codifiable in legal contracts specifying the exact roles and responsibilities of all parties involved. This is why contracts are only of limited value in joint $\mathrm{Ph}$.D. projects and partner organizations rely primarily on mutual trust and ongoing cooperation. If mutual trust is established before the start of the project, or if such trust can easily be established during the project, two partners are more likely to accept a shared governance structure. By contrast, if this trust is not already established nor easily created, the partners are more likely to settle for a centralized governance structure, for example, on the basis of who funded the project.

Below, we apply a proximity framework to probe the conditions that facilitate a shared governance mode in research collaboration (Rallet and Torre 1999; Boschma 2005). In most studies, the proximity framework is adopted to predict collaboration intensity: the more proximate two actors are, the more likely they collaborate in joint research projects (Autant-Bernard et al. 2007; Ponds et al. 2007; Balland 2012). Here, we are not interested in the collaboration frequency between organizations, but in the mode of governance they apply under varying conditions.

\section{Theoretical background}

\subsection{Proximity, resources and governing mode}

It has become common to distinguish five forms of proximity: geographical, social, institutional, cognitive, and organizational (Boschma 2005). Each form of proximity refers to a particular characterization of the relationship between two actors, where proximity refers to some kind of similarity, and its reverse, being distance, ${ }^{1}$ refers to some kind of dissimilarity. Our main hypothesis holds that organizations which are distant will find it more difficult to create conditions of trust and are thus less likely to opt for a shared mode of governance. Though shared governance provides a better basis for mutual collaboration

\footnotetext{
1 Note that our theoretical framework reasons from 'proximity', whereas our hypothesis and relevant variables are consistently defined in terms of 'distance', being the opposite of proximity.
} 
among equal partners (Shrum et al. 2007), it is also likely to introduce ambiguities and potential conflicts regarding decision-making authority (who decides in which case?), principles (what is the project's main objective and underlying value?) and routines (how did we make decisions in the past in similar contexts?) (Torre and Rallet 2005). If partners are already proximate while entering a partnership, be it geographically, cognitively or socially, trust is easier to establish, and a shared governance is more likely to be effective. Hence, proximate partners are expected to prefer a shared governance mode over a governance mode that is centralized at one partner. Instead, distant partners will more likely organize governance either at the university or at the university's partner organization given that the conditions to create a common basis of mutual trust and understanding are less favorable. Whether they centralize governance at the university or at their partner, will in turn depend on both partners' relative strategic interest in the project.

Geographical distance refers to distance in physical space. The benefits from geographical proximity in joint innovation projects have been highlighted mainly with reference to the need for face-to-face interactions (Boschma 2005). Indeed, tacit knowledge is easier transferred through face-to-face interaction, which in turn is easier to organize when partners are located in close vicinity. Furthermore, the more distant two partners are located from each other, the more time and resources are required for meetings, the less frequently meetings can take place, and the more difficult it will be to create mutual trust (Cummings and Kiesler 2005; Ponds et al. 2007; Bouba-Olga et al. 2012). In such instances, centralizing governance at one location rather than distributing it over two locations is more practical, as governance requires face-to-face interaction. By contrast, partners co-located in close vicinity may opt to share governance over its two locations. Hence, our hypothesis holds:

Hypothesis 1a As the geographical distance between partners increases, a shared governance mode becomes less likely

Social distance refers to what extent actors are unacquainted with each other. This can range from being close friends to being complete strangers. In previous analyses of research collaboration, social proximity has been referred to as the extent to which two actors have collaborated in the past on previous projects (Bouba-Olga et al. 2012). The continuation of a relationship can be seen as an indication of success (Salimi et al. 2013), which creates trust among partners. Hence, the common experience will greatly facilitate the organization and management of a following project, making it more likely that roles and responsibilities are shared. Conversely, first time collaborations are characterised by social distance. Hence, the sharing of responsibilities will be more difficult to achieve and governance is more likely to be centralized. According to this reasoning:

Hypothesis 1b As the social distance between partners increases, a shared governance mode becomes less likely

A third type of distance concerns cognitive distance, which refers to the extent to which partners have a different knowledge base (Nooteboom 2000). This form of distance is possibly the most challenging in research collaboration, because a lack of common knowledge hampers effective communication and interpretation. In cases where collaborators lack a common understanding, it will be difficult to establish trust because one partner's claims are hard to validate by the other, and vice versa. Consequently, a shared mode of governance is less likely. Instead, one would expect governance to be centralized at the partner who is most familiar with and knowledgeable about the subject matter. Hence: 
Hypothesis 1c As the cognitive distance between partners increases, a shared governance mode becomes less likely

Another form of distance in research collaboration concerns institutional distance. Actors are said to be institutionally distant when they operate under a different set of norms, values and incentives (Ponds et al. 2007). For example, a university-industry collaboration is characterised by institutional distance, as firms have different incentives (to apply knowledge and to make profit) than a university (to seek novelty and to publish results). By contrast, an inter-university collaboration or an inter-firm collaboration can be characterised by institutional proximity, since actors in such collaborations have very similar incentives. Given that our study only deals with collaborations between a university and external partners, all relations are by definition institutionally distant. However, our data include both collaborations between a university and a firm, as well as those between a university and a PRO. Thus we have added as a variable a dummy "industry" to distinguish university-industry relations from university-PRO relations.

Finally, organizational distance is a fifth type of distance and generally refers to the extent to which collaborators operate autonomously. Conversely, organizational proximity refers to the extent that collaborators are governed under a hierarchical relationship (e.g. two subsidiaries of a single firm). In our study, we deal with collaboration between two different organizations. Hence, the relationship is by definition characterized by organizational distance, which is why no hypothesis will be developed regarding the organizational dimension.

A second factor that affects the governance mode is resource imbalance. In particular, once one of the partners holds resources that are critical, such as data and research facilities, this partner will probably be reluctant to share project management and decisionmaking. In such contexts of resource imbalance, a shared governance mode is less likely for at least two reasons: strategic and pragmatic. Strategically, the holder of critical resources is interested in temporarily sharing resources for their joint exploitation, and not in transferring these resources on a permanent basis. By temporarily granting access to critical research resources such as data or facilities to external partners, an organization runs the risk of losing its competitive advantage in the longer term. Hence, the granting partner will be more prone to stay in control of the exact course and content of the research project. And, pragmatically, there are reasons to centralize governance at the partner holding the critical resources. The use of critical resources in research projects requires the possession of complementary tacit knowledge. As this knowledge is primarily centralized with researchers employed by the partner granting access to the resources, management and decision-making will mostly be allocated to those with the most knowledge about the productive use of the resources. Hence:

Hypothesis 2 If one of the partners holds critical resources, it is more likely to control the governance

A typical feature of research projects is that resources are not only being used, but also being created. Resources such as data, software and research facilities are not only potential inputs, but also potential outputs. Furthermore, a Ph.D. project essentially involves the training of the Ph.D. candidate, that is, the creation of human capital. Actually training of the Ph.D. doctorate which is the highest degree in academia is considered as an investment in human capital (Mangematin 2000). Not only investing in the Ph.D. degree is important for the students because of the positive relationship between having Ph.D. degree and rate of employment and salaries, but also the characteristics of human capital in 
terms of their level of education, knowledge and skills are critical for firms (Hitt et al. 2001). Although partners, almost by definition, only enter into collaboration if both have something to gain, the distribution of the resulting output may be imbalanced. For example, some projects are initiated by the university because it foresees interesting research opportunities, while other projects are initiated by a university's partner, for example when a key employee wishes to obtain a Ph.D. degree. Though motivations can be many, if one of the two partners is the sole project funder, this can be seen as "revealed" evidence that the main interest in the project lies with that partner. Hence:

Hypothesis 3 If one of the partners is the sole project funder, it is more likely to control the governance

\subsection{Proximity, resources and disclosure}

What probably causes the most specific tension in university-industry projects are the divergent incentives between universities and their partners regarding the disclosure of research output (Etzkowitz and Leydesdorff 2000; Dasgupta and David 1994). University researchers, almost without exception, are evaluated by the research output they generate (mainly in the form of scientific papers) and its impact in the scientific community (mainly in the form of citations). This means that they will be eager to publish the research output of a joint Ph.D. project as widely as possible. Furthermore, they have an incentive to publish their results quickly as competing research teams may pre-empt them, lowering their (citation) impact. While university patenting (often combined with publication restrictions) is becoming increasingly important, it is still a relatively rare phenomenon in most countries.

Firms, by contrast, develop knowledge with a commercial application in mind. Given the competition from fellow firms, the public disclosure of research output would render this knowledge accessible to competing firms. Hence, firms have an interest not to disclose research output, or at least put restrictions on what is exactly being disclosed and when.

Importantly, there are situations where tensions regarding publication may be negligible. For example, some firms are interested in co-producing scientific research as a means of building 'absorptive capacity', that is, the capacity to understand and make use of knowledge produced elsewhere (Cohen and Levinthal 1990; Rosenberg 1990). Firm employees who engage in scientific research activities are also better able to exploit the cutting-edge scientific knowledge produced elsewhere and published in the public domain. Once the results are published, other firms only have access to the codified part of the knowledge produced, while the absorptive capacity remains proprietary.

Restrictions on the publication of results stemming from a joint Ph.D. project can be considered a special mode of governance. Obviously, restrictions will be more likely if the university collaborates with a firm rather than with a PRO. The latter usually has a similar interest in disclosing results as quickly and widely as possible, given their public mission. That is, PROs are more proximate to universities than firms, because their incentive structure resembles the university structure more than that of firms. Therefore we can put forward the following hypothesis:

Hypothesis 4 Industry involvement renders publication restriction more likely

Resources, again, are also expected to play a role in publication restrictions. The particular imbalance in critical resources can affect the dominant institutional logic. If the university holds the critical resources, it can be expected to grant a university partner 
access to these resources provided that results can be published without restrictions. This outcome is likely because the university has a stronger negotiating position than the firm. Conversely, if the university's partner holds the critical resource, the partner can be expected to put restrictions on publications, as a means to protect their resource from competitors. Such an outcome is likely because, in this context, the university's partner has a stronger negotiating position than the university. Thus the following hypotheses can be derived:

Hypothesis 5a If the university holds critical resources, publication restriction is less likely

Hypothesis 5b If the university's partner holds critical resources, publication restriction is more likely

Similarly, negotiating positions will differ according to the funding source. If one of the actors is the sole funder of the project, it is likely that the institutional logic of the funding organization applies. This means that if the university finances the entire project from its own funds, it will be unlikely to accept any restrictions on publication, while if the university's partner funds the entire project, it is more likely that publication restrictions will apply. Hence:

Hypothesis 6a If the university is the sole project funder, publication restriction is less likely

Hypothesis 6b If the university's partner is the sole project funder, publication restriction is more likely

\subsection{Overview of hypotheses}

Based on our theoretical outline, we have developed a total of ten hypotheses. We have put forward five hypotheses regarding the choice of a shared or centralized mode of governance and five hypotheses on the option of putting restrictions on the disclosure of results in the form of publications. Table 1 provides an overview of the hypotheses in our study.

\section{Methodology and data}

\subsection{Data collection}

Our empirical analysis is based on data from collaborative Ph.D. projects at the Eindhoven University of Technology that resulted in published doctoral theses. We analyzed all such theses published between the years 2000 and 2011 in all departments of the university. ${ }^{2}$ Data was gathered by asking the Ph.D. candidates $^{3}$ who conducted these collaborative

\footnotetext{
${ }^{2}$ Departments concern Applied Physics, Chemical Engineering, Electrical Engineering, Mathematics and Computer Sciences, Mechanical Engineering, Built Environment, Biomedical Engineering, Industrial Design, Industrial Engineering and Innovation Sciences. The latter four departments where categorized in a single category Management/Design in the regression analysis.

${ }^{3}$ In terms of context, it might be good to explain here that in The Netherlands, Ph.D. candidates typically have an employment contract with the university and receive a regular salary. In that sense, involving them in a collaboration with a firm should probably not be seen a form of exploitation of these individuals.
} 
Table 1 Overview of hypotheses

Hypotheses regarding modes of governance

Hypothesis 1a: As the geographical distance between partners increases, a shared governance mode becomes less likely

Hypothesis 1b: As the social distance between partners increases, a shared governance mode becomes less likely

Hypothesis 1c: As the cognitive distance between partners increases, a shared governance mode becomes less likely

Hypothesis 2: If one of the partners holds critical resources, it is more likely to control the governance Hypothesis 3: If one of the partners is the sole project funder, it is more likely to control the governance Hypotheses regarding publication restriction

Hypothesis 4: Industry involvement renders publication restriction more likely

Hypothesis 5a: If the university holds critical resources, publication restriction is less likely Hypothesis 5b: If the university's partner holds critical resources, publication restriction is more likely Hypothesis 6a: If the university is the sole project funder, publication restriction is less likely Hypothesis 6b: If the university's partner is the sole project funder, publication restriction is more likely

$\mathrm{Ph} . \mathrm{D}$. projects to fill in a questionnaire. We included the university's collaborations with both firms and PROs, which are to some extent similar in The Netherlands in that both rely heavily on external sources to fund research and both value technology development at least as important as knowledge creation. ${ }^{4}$ We excluded collaborations with other universities and (other) governmental bodies, as we believe that such collaboration are rather different in nature. We also excluded collaborations with three or more partners.

Whether a particular Ph.D. thesis resulted from collaboration, was determined by reading the abstract, acknowledgements and other relevant front matter of these documents. Of the total of $1783 \mathrm{Ph} . \mathrm{D}$. theses in the specified period, we identified $496(28 \%)$ that had resulted from a collaboration with either a firm or a PRO. (From here on, both groups will be referred to as 'university's partner' or 'partner'.) Through various methods, we were able to find up-to-date contact details of the former Ph.D. candidates for 408 of these 496 collaborations. Each individual was approached with the request to submit a questionnaire, in other words we did not draw a sample but contacted the full population. After sending two subsequent reminders, we received 191 completed questionnaires, which is a response rate of $47 \%$. To check for possible non-response bias, we used the projected respondent method offered by Armstrong and Overton (1977). This method assumes that non-respondents are more similar to late respondents. After analyzing the differences between several waves of respondents, we found no serious concerns regarding nonresponse bias.

The received responses are almost evenly split between collaborations with firms (53\%) and those with PROs (47\%). Given the presence of a number of large technology companies in the Eindhoven region, it will come as no surprise that firms such as Philips and ASML are well represented in the responses, but there are also numerous partners with only one or two collaborations. Of all the respondents, $130(66 \%)$ had the Dutch nationality, emphasizing the fairly international character of these candidates.

\footnotetext{
${ }^{4}$ Here, it is important to stress that in The Netherlands, most of these institutes rely heavily on contract research and other sources of commercial funding, and have very limited public funding, making them quite comparable to firms in many respects. We do realize this situation is notably different in most other countries.
} 
A consequence of our hypotheses is that we require data from all three partners' perspectives (university, Ph.D. candidate, and collaborating partner). In an ideal world, such data would be collected from all three sources. However, this approach would also have very serious drawbacks. First, it is often difficult to identify and find up-to-date contact information for all the relevant persons. Second, requiring all three completed questionnaires for each case we receive would have a dramatic effect on the total number of usable cases. ${ }^{5}$ Third, the supervisors at the university or partner institute may not very accurately remember the details of a specific collaboration, especially if they were involved in many $\mathrm{Ph} . \mathrm{D}$. projects and collaborations over a long period. In contrast, for the Ph.D. candidates, it was a once in a lifetime experience, which they are likely to remember in detail, resulting in higher data quality. Considering all the above, we decided to collect data by sending questionnaires only to Ph.D. candidates. ${ }^{6}$

We are aware, though, that using a single source may result in common method bias. To address this concern, we applied some remedies offered by Podsakoff et al. (2003). Among other things, we focused our questions as much as possible on actual facts, which were open to interpretation or opinion (e.g. who funded the research, or whether there was a publication restriction or not). We also piloted a concept survey with several members of the population, to ensure all questions were clear and understood the way we intended them, and to ensure that we offered the appropriate answering categories. On the basis of this pilot, we made a number of changes and added examples where helpful. Finally, in addition to remedies for preventing common method bias, to make sure there would be no common method bias after conducting the survey, we used Harman's one-factor test. In this method, all variables (dependent and independent) are entered into an exploratory factor analysis (Podsakoff et al. 2003). Based on the result of the factor analysis, nine factors were extracted, accounting for $73 \%$ of the total variance, with the first factor accounting for about $11 \%$ of the total variance. This suggests that our study does not suffer from common method bias.

\subsection{Description of variables}

According to our hypotheses, the dependent variables in our study concern the governance mode of the collaboration and potential publication restrictions. While the hypotheses only distinguish between 'centralized' and 'shared' governance modes, we actually collected more detailed data on the way these projects were governed, recognizing there might be different dimensions at play. As can be seen from Table 2, we measured both the management (such as daily supervision) as well as the decision-making aspects (relating more to one-time, fundamental and critical issues, such as the topic, the aims and objectives, and so on). In each case, we determined whether the prominent partner is the university (a centralized mode), the partner (also a centralized mode), or both (a shared governance

\footnotetext{
5 If we assume the response rate for all groups is identical to what we had for Ph.D. candidates (47 \%), and that non-response is independent between respondents, then the response rate for complete cases would be $.47 * .47 * .47=.104$ only, which would have left us with only 42 cases. Moreover, it is likely that the identification and response rate among supervisors at both university and partner are lower than those for Ph.D. candidates, which would result in even fewer cases.

${ }^{6}$ It also implied that we could not ask the university supervisor and the university's partner directly about the levels of trust, which-as we assume-affects the governance mode choice. Neither can one expect the respondent (the Ph.D. candidate) to be able to judge how trustful the relationship was between the collaborating partners. Instead, as explained in the theory section. We derive hypotheses based on the underlying theoretical arguments in the proximity literature.
} 
mode). Concerning our measurement of publication restrictions, we only considered the situation where the partner imposed such restrictions.

Table 3 reports the correlation between dependent variables. Not surprisingly, we thereby observed some degree of correlation between the management and the decisionmaking dimensions. Yet, they are certainly not perfectly correlated, which motivated us to test our hypotheses for both different dimensions. There appears to be no significant correlation between the governance modes and the publication restriction.

Table 4 provides an overview of the independent variables. As discussed in Sect. 2, we asked respondents to evaluate their Ph.D. projects in terms of three types of proximities and two types of resource indicators. For measuring geographical proximity, we considered whether the offices of university partners are located abroad or not (asking specifically whether the partner's offices were located in its supervisor's place of residence). Given the small size of the Netherlands, this variable captures geographical proximity as almost all Dutch cities can be reached within just $2 \mathrm{~h}$ from Eindhoven. As can be seen in Table 4, the geographical distance is low in 163 cases, and high in 28 cases. Social distance is measured by observing whether the collaborating organizations had previous relationships, as discussed above. We see that for most cases, the social distance is low (i.e. there have been previous relationships); in only 33 cases is the social distance high. Finally, cognitive distance was measured by asking the respondents to rate the university supervisor's level of knowledge on the specific research topic (on a five point Likert-type scale), as well as that of the partner's supervisor, and then consider the distance between these two ratings. Hence, we measure cognitive distance in the vertical sense (how much more does one partner know about the specific topic than the other) instead of cognitive distance in the horizontal meaning (how different is the knowledge the partners hold), as other have done (e.g. Nooteboom et al. 2007).

Our measurements for resource indicators are quite straightforward, simply asking the respondents to what degree either partner provided access to unique resources (where we provided a number of examples of such resources). For funding, we distinguish between projects funded by the partner, projects funded with the university's own budget, and 'other funds' (which notably include large public funding organizations such as the Dutch NWO and STW agencies, as well as personal scholarship).

We also measure industry involvement using a dummy, considering whether the university's partner is a firm (dummy $=1$ ) or a public research organization (PRO) (dummy $=0$ ). Out of 191 collaborations, 103 involved industry.

As part of our analysis, we also considered the effect of nine control variables. Table 5 presents these variables, which all relate to the motivation of the university or the partner to engage in the collaboration, and thus offer an alternative explanation of the phenomena we measured. (Below we provide more information on how we entered these control variables in our analyses.)

\section{Results and discussion}

Using binary logistic regressions, we tested our ten hypotheses for the effect of proximity and resource imbalances. A general overview of these regressions is shown in Table 6. Each of the Columns [1] to [6] has a different dependent variable relating to the governance mode, whereas for Column [7], the dependent variable is whether or not the partner imposed a publication restriction. 
Table 2 Descriptive statistics of dependent variables

\begin{tabular}{lll}
\hline Dependent variable & Value & $\mathrm{N}$ \\
\hline Prominent partner in managing the coordination & The university: $\mathrm{n}=88(46 \%)$ & 191 \\
& The partner: $\mathrm{n}=38(20 \%)$ & Both partners: $\mathrm{n}=65(34 \%)$ \\
Prominent partner in decision-making & By the university: $\mathrm{n}=93(49 \%)$ & 191 \\
& By the partner: $\mathrm{n}=37(19 \%)$ & \\
Publishing some results was restricted by university's partner & Beth partners: $\mathrm{n}=61(32 \%)$ & 191 \\
\hline
\end{tabular}

Table 3 Correlation between dependent variables

\begin{tabular}{lll}
\hline Variables & $\begin{array}{l}\text { Prominent partner in managing the } \\
\text { coordination }\end{array}$ & $\begin{array}{l}\text { Prominent partner in } \\
\text { decision-making }\end{array}$ \\
\hline $\begin{array}{l}\text { Prominent partner in } \\
\text { decision-making }\end{array}$ & $.492^{* * *}$ & $.188^{* *}$ \\
\begin{tabular}{l} 
Publication restriction \\
\hline
\end{tabular} & .084 & .184 \\
\hline
\end{tabular}

Phi coefficient was used to measure the association between dichotomous and categorical variables $* p<0.10 ; * * p<0.05 ; * * * p<0.01$

Table 6 shows that geographical distance has a significantly negative impact on both shared project management and decision-making based on mutual agreement, supporting Hypothesis 1a. As argued before, we believe that this high geographical distance between the university and its partner reduces the level of trust due to less and less frequent interaction and face-to-face communication between them (Ponds et al. 2007; Boschma 2005; Desrochers 2001). In these cases, the partners opted for centralized governance opposed to shared governance. Table 6 also shows that in such scenarios, the university is far more likely to perform the governance tasks than the partner. Perhaps this is because we also observed that the $\mathrm{Ph}$.D. candidate in most cases resided at close proximity to the university (not separately reported in this paper); thus there is a low spatial distance between this candidate and the university - and a high spatial distance between this candidate and the partner.

Regarding Hypothesis $1 \mathrm{~b}$, we found that, contrary to our expectation, social distance has a positive effect on shared management. Hence, this hypothesis regarding shared mode of management is rejected. Possibly, and different from geographical and cognitive distance, social distance may be a possible reason for choosing shared governance as both partners still need to know each other. By contrast, when partners have collaboration experience (social proximity), they are more likely to trust each other already, and it may be more likely that one partner governs the collaboration on behalf of the both. Our results further indicate that social distance among partners also have positive effect on the shared decision-making, but not significantly so.

Regarding Hypothesis 1c, we found no significant effect of differences between the level of knowledge at the university and its partner's supervisors (cognitive distance) on shared management. However, our results show that cognitive distance has a significant 
Table 4 Descriptive statistics of independent variables

\begin{tabular}{|c|c|c|c|c|c|c|}
\hline $\begin{array}{l}\text { Theoretical } \\
\text { concept }\end{array}$ & Independent variable & Values/mean & SD & Min & Max & $\mathrm{N}$ \\
\hline $\begin{array}{l}\text { Geographical } \\
\text { distance }\end{array}$ & $\begin{array}{l}\text { Country of the offices of the } \\
\text { main collaborating partner } \\
\text { (where supervisor of } \\
\text { collaborating partner was } \\
\text { located) is abroad }\end{array}$ & $\begin{array}{l}\text { The Netherlands: } \mathrm{n}=163 \\
(85 \%) \\
\text { Abroad: } \mathrm{n}=28(15 \%)\end{array}$ & & & & 191 \\
\hline Social distance & $\begin{array}{l}\text { No previous relationship } \\
\text { between supervisors from } \\
\text { both the university and its } \\
\text { partner before Ph.D. project }\end{array}$ & $\begin{array}{l}\text { Previous relationship: } \\
\mathrm{n}=140(81 \%) \\
\text { No previous relationship: } \\
\mathrm{n}=33(19 \%)\end{array}$ & & & & 173 \\
\hline $\begin{array}{r}\text { Cognitive } \\
\text { distance }\end{array}$ & $\begin{array}{l}\text { Differences between level of } \\
\text { knowledge of university } \\
\text { and its partner's supervisor }\end{array}$ & $.73(\text { on a scale of } 1-5)^{\mathrm{a}}$ & .805 & 0 & 3 & 187 \\
\hline \multirow[t]{2}{*}{$\begin{array}{l}\text { Critical } \\
\text { resources }\end{array}$} & $\begin{array}{l}\text { University holds critical } \\
\text { resources }\end{array}$ & 3.49 (on a scale of $1-5)$ & 1.190 & 1 & 5 & 171 \\
\hline & $\begin{array}{l}\text { Partner holds critical } \\
\text { resources }\end{array}$ & 3.39 (on a scale of $1-5)$ & 1.092 & 1 & 5 & 169 \\
\hline Funding & Ph.D. project funder & $\begin{array}{l}\text { Partner: } \mathrm{n}=109(57 \%) \\
\text { University: } \mathrm{n}=14(7 \%) \\
\text { Other: } \mathrm{n}=68(36 \%)\end{array}$ & & & & 191 \\
\hline $\begin{array}{l}\text { Industry } \\
\text { involvement }\end{array}$ & University's partner is a firm & $\begin{array}{l}\text { Firm: } \mathrm{n}=103(54 \%) \\
\text { PRO: } \mathrm{n}=88(46 \%)\end{array}$ & & & & 191 \\
\hline
\end{tabular}

a Please note that we consider the absolute value of knowledge difference among university and its partner supervisors

negative impact on shared decision-making, meaning that Hypothesis 1c regarding shared decision-making is confirmed.

Continuing with the role resources play in the mode of governance, we conclude that decision-making is indeed strongly dependent on the ownership of critical resources, such as data or research facilities. This result confirms Hypothesis 2. If the university holds these resources, this also has a positive effect on its likelihood of managing the project, but the same does not apply to partners. The fact that most Ph.D. candidates were resident in Eindhoven (the city which university is located) during the Ph.D. projects, may further explain why especially the university tends to centralize the day-to-day management when holding critical resources. Concerning Hypothesis 3, funding by the university or its partner does not increase its likelihood to manage the project, nor to centralize decisionmaking. Hence, we find no support for this hypothesis.

Finally, we consider in what situations publication restrictions occur. Our results in Table 6, Column [7] show that industry involvement (meaning the university's partner is a firm as opposed to a PRO), renders publication restrictions more likely. This result supports Hypothesis 4. We believe the firm's focus may be predominantly commercialization activities, and in this case, the disclosure of output can run the risk of knowledge leaking to a firm's competitors.

Ownership of critical resources (Hypothesis 5a and Hypothesis 5b) has no effect on publication restrictions. Concerning funding, partner funding increases the likelihood of publication restrictions (confirming Hypothesis 6b), while university funding does not reduce this likelihood (rejecting Hypothesis 6a). That is, universities do not seem to defend 
Table 5 Descriptive statistics of control variables

\begin{tabular}{|c|c|c|c|c|c|}
\hline Control variable & Mean & SD & Min & $\operatorname{Max}$ & $\mathrm{N}$ \\
\hline \multicolumn{6}{|l|}{ Motivation of collaborating partner } \\
\hline $\begin{array}{l}\text { A need for a very specific piece of knowledge to fill an } \\
\text { existing knowledge gap }\end{array}$ & 3.58 & 1.154 & 1 & 5 & 174 \\
\hline $\begin{array}{l}\text { A more general increase in the organization's longer-term } \\
\text { stock of knowledge in a specific area }\end{array}$ & 3.70 & .987 & 1 & 5 & 169 \\
\hline $\begin{array}{l}\text { Promoting employee to obtain a Ph.D. (in cases where } \\
\text { the Ph.D. candidate was employed by the collaborating } \\
\text { partner prior to the Ph.D. project) }\end{array}$ & 2.67 & 1.389 & 1 & 5 & 130 \\
\hline Creating and maintaining linkages to universities & 3.73 & .984 & 1 & 5 & 177 \\
\hline \multicolumn{6}{|l|}{ Motivation of university } \\
\hline Collaboration was required to obtain public funding & 2.83 & 1.428 & 1 & 5 & 134 \\
\hline Attractiveness of research topic & 3.94 & .829 & 1 & 5 & 173 \\
\hline Alignment of university research with industry needs & 3.57 & 1.170 & 1 & 5 & 172 \\
\hline Contributing to the regional or national economy & 2.64 & 1.141 & 1 & 5 & 143 \\
\hline Creating and maintaining linkages to industry & 3.74 & 1.116 & 1 & 5 & 170 \\
\hline
\end{tabular}

All variables measured on a Likert-like scale ranging from 1 (strongly disagree) to 5 (strongly agree)

an open publication attitude in such collaborations, even when they have the bargaining power to do so (by owning critical resources). This is in contrast to what we expected from a university's primary mission. Furthermore, as we mentioned, our results show that in cases where projects are funded by a partner or even by the university itself, publication restrictions increase. It is clear that in the first situation, the partner as a funder stays in power so imposes publication restrictions. However, in the second situation (university is a project funder), it seems that the university partner tries to maintain the power balance by placing restrictions. We need to stress, however, that regardless of the effects we found, publication restrictions remain rare, as can be seen in Table 2.

As there might be alternative explanations for the evaluated phenomena, we performed robustness checks by adding nine control variables, all relating to the motivation of either the university or the partner to collaborate (see Table 5). However, in order to prevent losing a degree of freedom unnecessarily, we opted to include the control variables one by one, each time checking whether the conclusions regarding the confirmed hypotheses were still valid. In our findings below, a high robustness score means that the initial effect also holds whatever control variable is added, and that the weaker the score, the more often the effect disappeared when one of the nine variables was added.

Table 7 shows an overview of the results of our robustness checks for each of the accepted hypotheses. As can be seen, the robustness scores do tend to vary. In particular, the effect of funds at the partner organization on the decision to restrict publication (Hypothesis 6b) can be said to be little robust, as this effect was only found in three of the nine regressions that included a control variable. The remaining hypotheses confirmed in the initial analysis were found to be robust in at least five out of nine regressions.

We also included the different university departments as additional variables to control for disciplinary differences (not separately reported in this paper). We did not find any difference between departments as after adding all departments one by one to our models. 


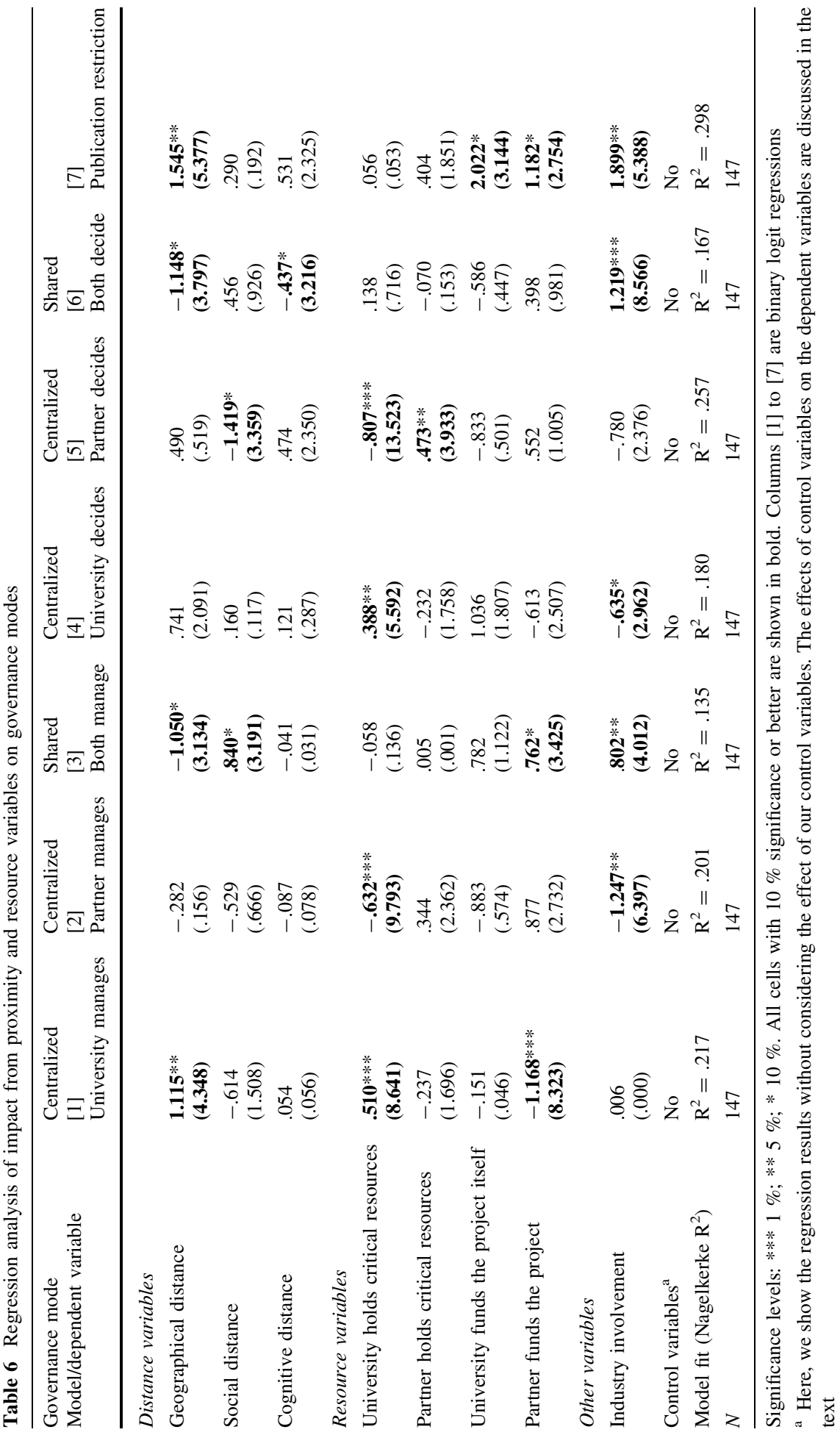




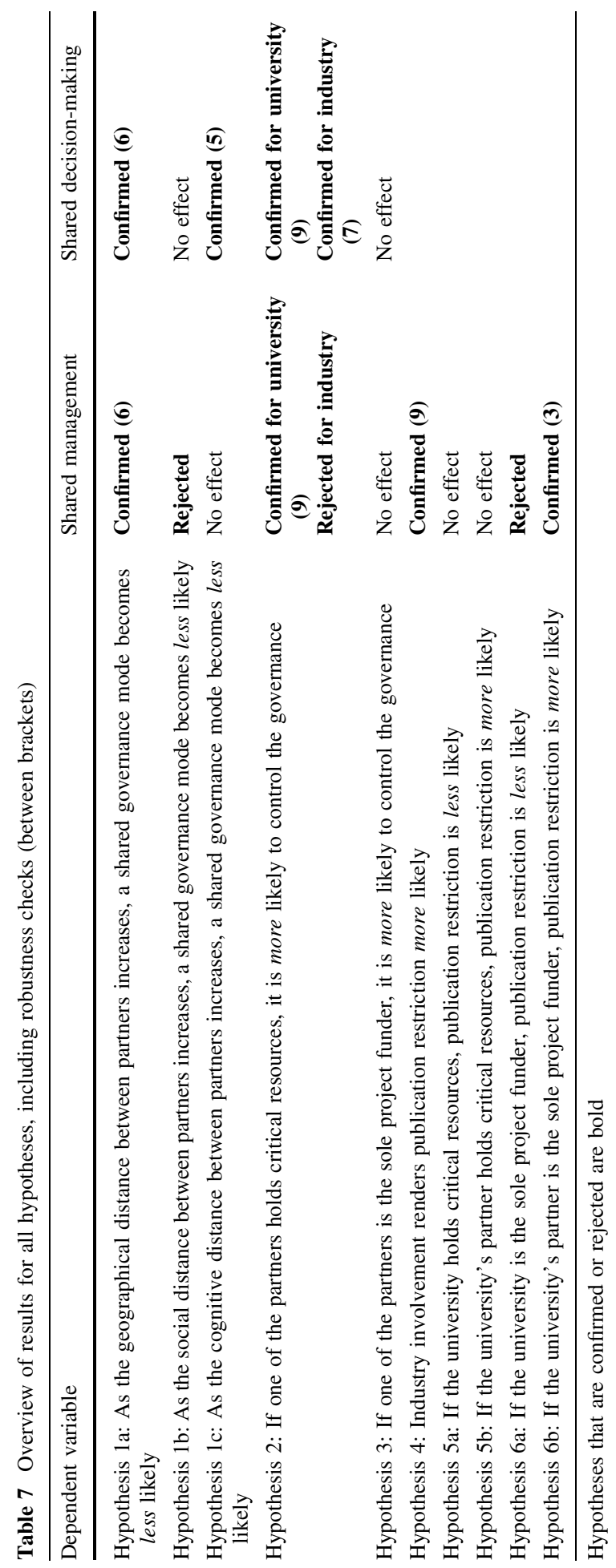




\section{Conclusions, implications and future research}

Our empirical study adds to the burgeoning field of university-industry relations in two ways. First, it deals with joint $\mathrm{Ph} . \mathrm{D}$. projects, which is a seriously underexplored topic in this area. Hitherto, the main focus has been on university patenting and licensing and on university spinoffs. However, as stressed recently by Perkmann et al. (2013), the "academic engagement" of universities towards industry is much more varied and multifaceted, and includes, among other channels, joint Ph.D. projects. Our study aimed to fill this gap by investigating the conditions that affect the governance mode choice in joint Ph.D. projects. Second, we have gone beyond previous statistical studies on university-industry relations, which only tested whether various forms of proximity affect the number of university-industry collaborations (Ponds et al. 2007; Balland 2012; Bouba-Olga et al. 2012; D'Este et al. 2013). We looked, instead, into the nature of university-industry collaborations by distinguishing various governance modes. In doing so, we could investigate whether shared governance modes are more likely among proximate partners.

In summary, this study finds three main robust results, which confirmed our hypotheses: (1) geographical distance renders the choice for shared management and shared decisionmaking less likely; (2) the partner controlling critical project resources tends to centralize project governance, and (3) partnering firms are more likely to put restrictions on publication output than public research organizations. We further found that, as expected, cognitive distance rendered shared decision-making less likely, but no such effect was found on shared management. Regarding social distance, we found that — unexpectedly-it increased the likelihood of shared management. No effect of social distance on shared decision-making was found.

We believe our conclusions have implications not only for universities wanting to improve the performance of collaborations, but also for their partners. As earlier research (Salimi et al. 2013) has shown that projects adopting a shared governance are more successful than those adopting a centralized governance mode, one may consider the conditions that favor shared governance in future project selections. As geographical and cognitive distance make the adoption of a shared mode of decision-making less likely, universities are recommended to either: (1) be selective in choosing collaborations and favor those collaborations where partners are located nearby and have a similar knowledge level, or (2) not to select on the aforementioned aspects, but insist on having a shared governance by sharing both decision-making and project management tasks, even though that might require additional investments in time and resources from both collaborators. Furthermore, we believe that when it comes to accepting publication restrictions, universities could be more critical than they are at present. While universities may not always be in a position to bargain, they can certainly do so if they have critical resources. Our results show that even in such cases, universities often do not make use of their bargaining power to ensure open publication.

Our recommendations to universities' partners (firms and public research organizations) mirror to a large degree our recommendations for universities. We advise them to seek collaboration with universities that are located relatively nearby. Given our findings that with long-distance collaboration, the Ph.D. candidate usually resides close to the university anyway, choosing a near-by university provides other advantages also to the partner. If one, nevertheless, enters into a long-distance collaboration (for instance because the institute located further away is more attractive in terms of its expertise), then the partner should be willing to spend additional resources and time to ensure that shared governance is achieved, thus improving the chances of high output. Concerning cognitive proximity, 
the implication for partners would be to allocate supervisors who have a knowledge level on the specific topic that is roughly in the same range as that of the allocated university supervisor. In that case, a shared governance mode becomes more likely and this in turn affects the probability of a project's success.

Our study has a number of limitations, some of which suggest avenues for further research. To begin with, all our cases are from one single university (Eindhoven University of Technology). Even though this university has no strict guidelines on Ph.D. collaborations, with faculty members having a large degree of freedom to design their collaborations, we cannot exclude some aspects being university-specific. In order to be able to generalize this for other institutions, other national contexts, and other disciplines, we hope future studies can test our findings in different settings. Regarding the national setting, we have operationalized our geographical distance as whether both collaborative partners were located in the Netherlands, or not. Given the small size of the Netherlands, we regard this as an obvious choice, since all distances between the university and national partners can easily be travelled within one working day. In a larger country, however, the longer distances could have quite different implications, and more refined conceptualizations of distance could be explored. A further limitation is that we have only considered successfully concluded Ph.D. studies, where success is defined as the Ph.D. candidate receiving the doctoral degree. We have not explored the relationship between governance modes and the likelihood of Ph.D. collaborations failing prematurely, for whatever reason. A study on Ph.D. failures in the context of collaborations could extend our understanding of this area. In this study we considered the characteristics of university and its partner such as cognitive differences, and social differences between them. However, characteristics of Ph.D. candidates in collaborative Ph.D. projects, and their proximity to the university and partner supervisors, may also influence the mode of governance. Furthermore, creation of knowledge requires different and complementary knowledge, which is the source of novelty and creativity (Boschma 2005). The investigation of effect of different and complementary knowledge of partners on the governance choices compared to the effect of similar knowledge base among partners on governance would deserves consideration. Moreover, considering other government bodies and universities would be interesting and deserves attention as one of the valuable future research in this filed. Finally, while we restricted ourselves to collaborative Ph.D. projects, future studies exploring governance modes across other types of collaborations (like R\&D) could complement the current insights.

Acknowledgments Earlier versions of this paper were presented at a research seminar held at Eindhoven University of Technology's department of Industrial Engineering and Innovation Sciences and at a colloquium at Delft University of Technology. We are very grateful for the comments and feedback provided by the participants. This paper also benefited from the valuable comments by three anonymous reviewers. We also thank Delft University of Technology's Transport and Logistics department for their support and use of their facilities.

\section{References}

Armstrong, J. S., \& Overton, T. S. (1977). Estimating nonresponse bias in mail surveys. Journal of Marketing Research, 14(3), 396-402.

Autant-Bernard, C., Billand, P., Frachisse, D., \& Massard, N. (2007). Social distance versus spatial distance in R\&D cooperation: Empirical evidence from European collaboration choices in micro and nanotechnologies. Papers in Regional Science, 86(3), 495-519. 
Balland, P.-A. (2012). Proximity and the evolution of collaboration networks: evidence from research and development projects within the global navigation satellite system (GNSS) industry. Regional Studies, 46(6), 741-756.

Boschma, R. A. (2005). Proximity and innovation: A critical assessment. Regional Studies, 39(1), 61-74.

Bouba-Olga, O., Ferru, M., \& Pépin, D. (2012). Exploring spatial features of science-industry partnerships: A study on French data. Papers in Regional Science, 91(2), 355-375.

Cohen, W. M., \& Levinthal, D. A. (1990). Absorptive capacity: A new perspective on learning and innovation. Administrative Science Quarterly, 35(1), 128-152.

Cummings, J. N., \& Kiesler, S. (2005). Collaborative research across disciplinary and organizational boundaries. Social Studies of Science, 35(5), 703-722.

Dasgupta, P., \& David, P. (1994). Towards a new economics of science. Research Policy, 23(5), 487-552.

Desrochers, P. (2001). Geographical proximity and the transmission of tacit knowledge. The Review of Austrian Economics, 14(1), 25-46.

D’Este, P., Guy, F., \& Iammarino, S. (2013). Shaping the formation of university-industry research collaborations: what type of proximity does really matter? Journal of Economic Geography, 13(4), 537-558.

Etzkowitz, H., \& Leydesdorff, L. (2000). The dynamics of innovation: From National Systems and "Mode 2 " to a Triple Helix of university-industry-government relations. Research Policy, 29(2), 109-123.

Gibbons, M., Limoges, C., Nowotny, H., Schwartzman, S., Scott, P., \& Trow, M. (1994). The new production of knowledge: The dynamics of science and research in contemporary societies. Beverley Hills, CA: SAGE Publications Limited.

Granstrand, O., Patel, P., \& Pavitt, K. (1997). Multi-technology corporations: Why they have'distributed'rather than'distinctive core'competences. California Management Review, 39(4), 8.

Hagedoorn, J., Link, A. N., \& Vonortas, N. S. (2000). Research partnerships. Research Policy, 29(4-5), 567-586.

Hitt, M. A., Biermant, L., Shimizu, K., \& Kochhar, R. (2001). Direct and moderating effects of human capital on strategy and performance in professional service firms: A resource-based perspective. Academy of Management Journal, 44(1), 13-28.

Liebeskind, J. P., Oliver, A. L., Zucker, L., \& Brewer, M. (1996). Social networks, learning, and flexibility: Sourcing scientific knowledge in new biotechnology firms. Organization Science, 7(4), 428-443.

Mangematin, V. (2000). Ph.D. job market: professional trajectories and incentives during the Ph.D. Research Policy, 29(6), 741-756.

Nooteboom, B. (2000). Learning and innovation in organizations and economies. Oxford: Oxford University Press.

Nooteboom, B., Van Haverbeke, W. P. M., Duijsters, G. M., Gilsing, V. A., \& Van Oord, A. (2007). Optimal cognitive distance and absorptive capacity. Research Policy, 36(7), 1016-1034.

Nuvolari, A. (2004). Collective invention during the British Industrial Revolution: The case of the Cornish pumping engine. Cambridge Journal of Economics, 28(3), 347-363.

Perkmann, M., Tartari, V., McKelvey, M., Autio, E., Broström, A., D’Este, P., et al. (2013). Academic engagement and commercialisation: A review of the literature on university-industry relations. Research Policy, 42(2), 423-442.

Podsakoff, P. M., MacKenzie, S. B., Lee, J.-Y., \& Podsakoff, N. P. (2003). Common method biases in behavioral research: A critical review of the literature and recommended remedies. Journal of Applied Psychology, 88(5), 879-903.

Ponds, R., Van Oort, F., \& Frenken, K. (2007). The geographical and institutional proximity of research collaboration. Papers in Regional Science, 86(3), 423-443.

Powell, W. W., White, Douglas R., Koput, Kenneth W., \& Owen-Smith, Jason. (2005). Network dynamics and field evolution: The growth of interorganizational collaboration in the life sciences. American Journal of Sociology, 110(4), 1132-1205.

Rallet, A., \& Torre, A. (1999). Is geographical proximity necessary in the innovation networks in the era of global economy? GeoJournal, 49(4), 373-380.

Rosenberg, N. (1990). Why do firms do basic research (with their own money)? Research Policy, 19(2), $165-174$.

Salimi, N., Bekkers, R., \& Frenken, K. (2013). Governance and success of university-industry collaborations on the basis of Ph. D. projects: An explorative study. Eindhoven Center for Innovation Studies (ECIS), working paper, No. 13.05.

Shrum, W., Genuth, J., \& Chompalov, I. (2007). Structures of scientific collaboration. Cambridge, MA: The MIT Press.

Teece, D. J. (1986). Profiting from technological innovation: Implications for integration, collaboration, licensing and public policy. Research Policy, 15(6), 285-305. 
Thune, T. (2009). Doctoral students on the university-industry interface: A review of the literature. Higher Education, 58(5), 637-651.

Torre, A., \& Rallet, A. (2005). Proximity and localization. Regional Sciences, 39(1), 47-59.

Williamson, O. E. (1975). Markets and hierarchies (pp. 26-30). New York: Free Press. 